LUIS ASTEY

\title{
Antigua sofística: fragmentos y reelaboraciones
}

\section{En otros géneros discursivos - sometido, por tanto, a 3. otras leyes de construcción- se conserva el pensamiento de la primera sofística ${ }^{16}$ acerca del hombre, los dioses y la}

16 Para la sofística antigua acepto en principio el canon establecido por A. Levi, Storia della sofistica, ed. D. Pesce (Nápoles, 1966), 333 (en la p. 28 se describe el criterio que presidió su fijación) y, en lo fundamental. confirmado por A. Gómez. Robledo, Platón: los seis grandes temas de su filosofia (México, 1974 =Gómez Robledo 1974; hay reimpresión de 1982), 478-79. Pero, a diferencia de este últimó, no excluyo una parte (ver sus pp. 494-95) de la que Levi denomina escuela de Protágoras y, con perdón de ambos especialistas, acojo, quizás injustificadamente, al "rettore semisofista" Trasimaco de Calcedonia, por el peso que el prefijo "semi" tiene en el libro primeramente mencionado (capitulo III). Y me represento esa misma sofística como un esfuerzo, serio y respetable, orientado en dos direcciones En primera instancia, hacia la tarea de "educar a los hombres". Así define su oficio Protágoras en el homónimo diálogo (317b) de Platón - ver Platón, Oéurres complètes, 111 1: Protagoras, ed. y trad. A. Croiset y L. Bodin (2a. ed.; París, 1948; Collection des Universités de France). 31. así como la p. 84 en Marrou 1960, obra que será identificada un poco más adelante - y análoga fue, según todos los testimonios válidos, la práctica de los demás sofistas incluidos en el canon. Si bien es necesario hacer constar que, lo mismo en el caso de éstos que en el de Protágoras y por muy subversiva que haya aparecido ante los ojos de sus contemporáneos más conservadores o de los epígonos de éstos, dicha práctica se ejerció dejando siempre intactas todas las limitaciones de orden social que la aplicación en sentido pleno de la palabra 'hombre'a los seres humanos individuales comportaba en la Atenas del siglo V a JC. Y, en segundo lugar, aunque con no menor interés, hacia el empeño de fundamentar esa educación en un examen de las posibilidades de aquellos mismos hombres en cuanto a su puesto en el mundo y a su actividad dentro de él, es decir, en cuanto a su condición como sujetos de la cultura. Este modo de entender la sofística antigua queda colocado, entonces, más acá tanto del punto de mira desde el que la enfoca Platón - aun cuando en él sea preciso distinguir, de la actitud irónica y despectiva con respecto a los sofistas como género, por una parte la innegable ambiguiedad ante la contextura de Protágoras y por otra el juego a las definiciones a que el extranjero de Elea, en algo que es al mismo tiempo un rigurosísimo ejercicio de metafísica y de lógica, se entrega durante numerosas páginas (22lc268d) en el Sofista (c. 361 a JC)-como de la que pudiera considerarse perspectiva 
participación de éstos y aquél en el acontecimiento de la cultura. $\mathrm{O}$, mejor, lo que de ese pensamiento ha sobrevivido: (a) cuatro citas, al parecer directas, retiradas de textos de Protágoras, de Trasímaco y de Pródico; (b) tres segmentos de un tratado de Antifonte: Sobre la verdad; (c) dos de siete extractos, éstos tal vez de obras diferentes pero referibles a un solo autor, no identificado, activo hacia fines del siglo $\mathrm{V}$ a JC - extractos que constituyen lo que se conoce como ‘Anónimo de Jámblico'; (d) cuatro parlamentos, presentados bajo ficción de oralidad y diversamente marcados según las intencionalidades de los escritos en que aparecen, respectivamente atribuidos a Protágoras, a Trasímaco y, dos, a Hipias en la medida en que los tres operan a modo de voces interlocutorias dentro de algunos diálogos de Platón o en los Memorabilia de Jenofonte; y (e) algunas citas en diversos escritos de Aristóteles, o en sus escolios.

Acaso no resulte completamente inadecuado distribuir y revisar estos testimonios en función de la componente particu-

común a la tendencia socrática 'ortodoxa': ni Jenofonte en el Cinegético (c. 401 a JC) XIII. 1-9 o en los Memorabilia (c. 386-c. 365 a JC) I 6, 13 (el pasaje pertenece a la fecha más temprana), ni Aristóteles en las Refiutaciones (entre 347 y 335 a JC) 1, 165a 21 , se plantean de otra manera el problema de la sofística. Ver sobre esto (a) Platón, El sofista. ed. y trad. A. Tovar (Madrid, 1955; Clásicos Políticos), 11-102; (b) Xenophon, "On hunting", en Scripta minora, ed. y trad. E. C. Marchant (Cambridge. Mass. y Londres, 1925; Loeb Classical Library, 183), 449-53; (c) Jenofonte, Recuerdos de Sócrates, Banquete, Apología, trad. J. D. García Bacca (México, 1946; Bibliotheca Scriptorum Graecorum et Romanorum Mexicana), 73; y (d) Aristotle. "On sophistical refutations", en On sophistical refutations, On coming-to-be and passing-away, ed. y trad. E.S. Forster [and] On the cosimos, ed. y trad. D. J. Furey (Cambridge, Mass. y Londres. 1955; Loeb Classical Library, 400), 13-15. Ya en el clásico libro de E. Zeller. Die Philosophie der Griechen in ihrer geschichtlichen Entwicklung dargestellt, 1 2: Vorsokratische Philosophie: Herakleitos, Empedokles, Atomisten, Anaxagoras; Sophisten. Tübingen 1859 -que, en lo que se refiere a los sofistas, sólo conozco por intermedio de traducción al francés: E. Zeller, La philosophie des grecs considérée dans son développment historique, I 2: La philosophie des grecs avant Socrate: les Eléates; Héraclite, Empédocle, les Atomistes, Anaxagore; les Sophistes, trad. E. Boutroux (París, 1882), 449-556 - creo advertir diversos indicios que permiten pensar en un considerable alejamiento relativamente a la perspectiva adoptada por los socráticos mayores (ver en particular la sección "Caractẻres généraux de la sophistique": pp. 479-94). Sin embargo, la representación de la sofistica que subyace a todo lo que a continuación viene en este apartado II deriva capitalmente de trabajos más modernos. Para la vertiente educacional y humanística del movimiento, de los capítulos "La sofística", "La llustración y la sofística" (pero sin discernimientos axiológicos entre moralidad, amoralismo o inmoralismo: ver pp. 486 y 494) y "L'apport novateur de la première sophistique", respectivamente en Jaeger 1936, I 303-46. Gómez 
lar desde la que cada uno de ellos se representa la totalidad del acontecimiento. ${ }^{17} \mathrm{Y}$, en los puntos en que parezca ser preciso, confrontarlos o complementarlos con textos místicos y filosóficos no procedentes de la reflexión de los primeros sofistas.

\section{A. El mundo del hombre}

\section{Es posible, entonces, situar en primer término la tesis con que Protágoras habría comenzado su Verdad (Alétheia) ${ }^{18}$ :}

Robledo 1974, 467-5II y II-I. Marrou. Histoire de l'élucation dans l'Antiquité (5a. ed.; París, 1960 = Marrou 1960; hay traducción al español, de la tercera edición, por N. M. Spinelli de Mazziotti: Buenos Aires 1965. con reimpresión en 1970), 81-98. Y de W. C. K. Guthrie. "The world of the sophists", en A history of Greek philosophy. III: The fifth-century. Enlightenment (Cambridge. 1969 =Guthrie 1969), 1-399, para sus implicaciones más estrictamente filosóficas. Aunque también es necesario dejar constancia de que asimismo en trabajos modernos reaparecen a veces. y aventajadas, las viejas posiciones: C. D. Tsatos, La filosofía social de los antiguos griegos, trad. C. A. Salguero-Talavera. México 1982 (no he podido controlar la fecha del original) añade a las tradicionales acusaciones venalidad, errabunde\%, ficción de sabiduría la de haber sido la primera sofística "la causa espiritual más fuerte que determinó el hundimiento del mundo griego antiguo" (sic: p. 49). Por último, y en otro orden de cosas. se habla, como se sabe, de una primera sofística o sofística antigua debido a que, en los siglos II a IV a JC. en el ámbito del mundo helenístico-romano se produjo un conjunto de escuelas de retórica y de oradores y conferencistas itinerantes que se han englobado bajo la denominación de segunda sofística. Son fuentes antiguas para ella las I'idas de sofistas (c. 230-238 d JC) de Filóstrato que también remiten a ciertos sofistas antiguos y las lidasdefilosofos y sofistas (c. $400 \mathrm{~d}$ JC) de Eunapio las dos recogidas en Philostratus and Eunapius, Lives of the sophists. ed. y trad. W.C. Wright, Cambridge. Mass. y Londres 1921, Loeb Classical Library 134. Y para una aproximación reciente ver E. L. Bowie. "The importance of the sophists", Yale Classical Situdies 27 (1982). 29-59.

17 Excepto, y a veces sólo a la larga, para lo conservado por Aristóteles o por Platón. ý quizá para algún otro caso que pareza requerirlo, me refiero a los textos procedentes de la antigua sofística o concernientes a ella según aparecen en la recopilación de H. Diels. Die Fragmente der I'orsokratiker: Griechisch und Deutsith. 5a. ed. por W. Kranz. I-III. Berlín 1935 (=DK). No me ha sido posible consultar directamente ediciones posteriores a ésta. Identifico los textos mediante los números y letras que en la mencionada recopilación han sido usados como instrumentos organizadores. He creido necesario añadir, a veces, la localización por páginas, o inclusive por líneas.

Is Así llama Platón. en el Téeletes, 16lc. a la obra de Protágoras a la que esta proposición pertenece (ver luego, nota 25). Sexto Empírico (s. Il-III d JC). Contra los matemáticos (máthëma =saber en cuanto objeto de enseñanza). VII 60(=DK 80 B l) se refiere a ella como Katahállontes (=Demoledores o Derribadores, evidentemente del adversario y' sobreentendiéndose 'Ŕazonamientos' o cualquier otra traducción análoga de 'lógoì). Se discute si la misma obra es mencionada también mediante un tercer título: Acerca del ser (Perîố óntos), que usa Porfirio (232-c. $305 \mathrm{~d}$ JC) en un pasaje que le asigna Eusebio de Cesarea en su Preparación evangélica (c. $315 \mathrm{~d}$ JC). X 3 (=DK 80 B 2). E. Brodero, Protagora, I: Prolegomeni, vita, stile, dottrina (Bari, 1914), 
"De todas las cosas medida es el hombre, de las que son en cuanto son, de las que no son en cuanto no son (Pánton khrëmátōn métron estìn ánthrōpos, tôn mèn óntōn hōs éstin, tôn dè ouk ónton hōs ouk éstin)".19

Como se sabe, bajo la engañosa sencillez de su literali$\mathrm{dad}^{20}$ el enunciado encierra varias dificultades de lectura. 'En cuanto' procede ya de una elección interpretativa, y seguramente contribuye a incrementar el engaño: intenta concertar en un solo elemento léxico del español las dos posibles traducciones - 'que'(conjunción) y 'como' (=modo en que) - que en los correspondientes segmentos textuales griegos hos permite y que podrían asimismo ser entendidas como recíprocamente excluyentes. ${ }^{21}$ Además, donde carece de predicado, ¿en qué sentido ha sido escrito éstin? ¿Remite ya al hecho puro de existir o indica todavía, o simultáneamente, el de 'suceder asi', el de"ser eso verdaderamente ? Y, esto último, ¿en el nivel de las realidades $\mathrm{o}$ en el nivel de las aseveraciones? ${ }^{22} \mathrm{O}$, en otra

97. defiende la denominación "porque lo que sigue [a lạ mención del título] en el pasaje de Porfirio no es sino la traducción a diferente lenguaje filosófico del conocido axioma protagoreano" (el hombre como medida). Al parecer. prácticamente todos los demás especialistas atribuyen el tercer título a una obra diferente del propio Protágoras. Por otra parte, tanto Platón y Sexto Empirico. loca citatu, como Diógenes Laercio, V'iclas y opiniones de los filósofos mas ilustres (primet a mitad del siglo III d JC), IX 51 (=DK $80 \wedge 1$ ), atestiguan que la tesis se hallaba colocada al comien $r o$ del escrito.

19 Traduzco y translitero a partir de Sexto Empirico, Contra los matemáticos: VII 60 (ver nota anterior), que por lo menos desde Diels se considera como la fuente 'clásica' del texto. Unicamente en este pasaje. y en el de Diógenes laercio asimismo citado en la nota precedente, parece conservarse íntegro, en estilo directo y sin interpolación de comentarios el enunciado de Protágoras. De otras maneras lo manejan DK 80 A 13-14, 16. 2 la y B 1 secciones 2 y 3, asícomo Aristóteles, Metafísica $\mathrm{X}$ I, 1053a 38 y XI 6. 1062b 12, testimonios estos dos no registrados en DK. Es posible que en ediciones posteriores a la que uso (aún no totalmente en la sexta: ver $M$. Timpanaro Cardini, i sofisti: frammenti e testimonianze (2a. ed.: Bari. 1954). XV y 15. n. 1) ya hayan quedado recogidos. En las siguientes notas $23,25.28$ y 36 hay traducciones, parciales o completas, tanto de los dos lugares de la Metafisica como de los incluidos en DK.

20 Compárece Jaeger 1936. I 317: "La célebre frase de Protágoras: 'El hombre es la medida de todas las cosas" tan característica en su misma ambigiuednd del tipo de su humanismo" (subrayado mio).

21 El alemán en DK 80 B I opta por mantener la disyunción: “... der seienden. dass (wie) sie sind, der nicht seienden, dass (wie) sie nicht sind" (II 263).

22 Para el sentido no existencial. o no puramente existencial, de einai en construcciones absolutas, ver $\mathrm{Ch}$. H. Kahn. "The Greek verb 'to be' and the notion of being". Foundations of Language: International Journal of language and Philosophy. 2(1966). 245-62. La tesis de Protágoras es tratada particularmente en las pp. 249-50. 
dirección, ¿qué son khrémata? Desde luego, no las cosas como ajenas al hombre. Tampoco prágmata o ni siquiera ónta, otros términos con que las cosas pueden ser significadas, ${ }^{23}$ las apar-

en conexión con el sentido "veridico" del verbo y la "esencial ambigüedad" de ese sentıdo (ver p. 252).

2. Prágmara (cf. 'praxis') liga las cosas al hombre a través de la actividad yue éste ejerce sobre ellas, pero configurándolas y mediatizándolas por la presencia, siempre en primer plano. de esa misma actividad. Al español, su traducción general más adecuada. puesta en singular. acaso sea 'asunto' (aquello que ha sido asumido o tomado a cargo por alguien. a lo que alguien ha constituido o tenido que constituir en objeto de su ocupación). Así por ejemplo en Esquilo, Eilménides, vv. 475-476, sólo que entre dioses antropomorfos (habla el coro de las Erinias): "Señor A polo, gobierna lo que te pertenece. Explica pues de qué modo tienes parte en estos asuntos (prágmata)" (=el matricidio, que ha sido actividad de Orestes, y la venganza de sangre, que tradicionalmente ha correspondido al área de ocupación de las Erinias). Y, también, con modificador o algún otro tipo de palabra que especializa su sentido, en Aristófanes y en Platón: “... asuntos y procesos (prágmara kantigraphái)". i.e.. asuntos legales: Nuhes (432 a JC). v. 471: “... los asuntos políticos (tà politikà prágmata)”: . Apología de Sócrates (c. 396 a JC). 31 d. O de parecida manera en Heródoto. pero dentro de un contexto que indirectamente remite al hombre como género: "Si crees ser inmortal y mandar tropar iguales a ti, no tengo necesidad alguna de exponerte mi opinión. Pero si reconoces que tú también eres hombre y mandas a otros que son como tú, piensa ante todo [en] aquello de que en los asuntos (pragmárōn: en genitivo a causa de la construcción griega) humanos hay una rueda que gira y no deja que siempre sean felices las mismas personas"(habla Creso a Ciro): /tistorias (c. 448-c. 428 a JC) I, 207. Para este último pasaje utilizo Heródoto. Historias, ed. y trad. J. Berenguer Amenós, I (Barcelona. 1960: Colección Hispánica de Autores (iriegos y Latinos), 134. En los casos anteriores traduzco de los textos en Platon. Oetures complètes. I: Introduction. Hippias mineur. Alcihiade, Apolegie de Socrate, Euthyphron, Criton. ed. y trad. M. Croiset (París 1953), 159; en Aristophane, I: Les Acharniens, les Cavaliers, les Nuées, ed. y trad. V. Coulon (París, 1948), 184; y en Eschyle, Il: Agamemnon, les Choéphores, les Euménides, ed. y trad. P. Mazon (Paris. 1965). 154 -todos en la Collection des Universités de France. K'hrémata, en cambio, tiene una connotación más apremiante: liga al hombre a las cosas desde la necesidad que él tiene de ellas, desde el valor de uso - y de cambio - que ellas le presentan. Ya en Odisea 2, vv. 78 y 203 (Homeri opera. ed. D.B. Monro y Th. W. Allen (3a. ed.; Oxford. 1920: Scriptorum Classicorum Bibliotheca Oxoniensis). II sin paginación) Telémaco llama khrếmata a los componentes de su patrimonio. es decir. al conjunto de los satisfactores con los que. en su privilegiada situación de noble, hace frente a las necesidades de su vida material - patrimonio que, dicho sea de paso. le interesa mencionar ante la asamblea de Itaca porque está siendo consumido por los cincuenta pretendientes de su prudente madre. $Y$, casi en el otro extremo del periodo helénico, en el capítulo I del Éconómico (c. 380? a JC) de Jenofonte, los bienes de este mundo (un caballo, la tierra, las ovejas, una flauta, el dinero: argírion) siguen siendo khrêmata, pero con una condición que Sócrates les impone en su diálogo con el propietario rural Aristóbulo, y ante la que es imposible no recordar el enunciado de Protágoras. En efecto. Sócrates dice: “... las mismas cosas (ónka), para el que sabe hacer uso (tổi mén epistaménôi $k$ hrêsthai) de ellas, son bienes ( $k$ hrếmata). y para el que no sabe. no son bienes" $(110)$. Y con la novedad. o no, de que. en este sentido, algunos hombres resultan 'crematizables': “... los amigos, si se sabe 
hacer uso de ellos de modo que beneficie su amistad "( ( 1 14) y "... los enemigos ... para el que sepa sacer partido de ellos" (1 15). Cito a partir de Jenofonte. Económico, ed. y trad. J. Gil (Madrid. 1967), 266-77. Por otra parte. entre la Odisea y el Económico. khrếmata experimenta una ampliación de sentido. Tal ve\% ésta se encuentre ya en Hesíodo, Los trahajos y los días (=Trabajos; s. VII a JC). v. 686: "El dinero [ila riquera!] es vida (psikhé) para los miserables hombres": Hésiode. Théogonie, les Travaux et les jours, le Bouclier, ed. y trad. P. Mazon (París. 1944: Collection des Universités de France). III. Pero ciertamente está en Alceo (s. VII-VI a JC): "El dinero es el hombre (khrếmat 'ánêr)": Poetartum leshiorum firagmenta. ed. E. Lobel y D. Page (Oxford, 1955). no. 360 (p. 275). Lo que Píndaro. Istmicas 2 (472 a JC). v. 11 , reelabora y amplifica: "El dinero, el dinero es el hombre": Pinclari carmina cum fragmentis, ed. C.M. Bowra (Oxford, 1935: Scriptorum Classicorum Bibliotheca Oxoniensis), sin paginación. $Y$, no inesperadamente, ese mismo significado de la palabra admite Platón en el Cratilo (c. 386-385 a JC), al retomar un tan predilecto tema suyo (ver antes, nota 16): “... seguir a los que saben, pagándoles dinero y, encima, dándoles las gracias. Son los sofistas ..."(39lb). Por lo demás, las perspectivas tienden a confundirse. y khrémata y prágmata se vuelven términos conmutables. Un solo ejemplo. De nuevo en el (ratilo (385e-386a) y precisamente en función de la tesis de Protágoras. Platón escribe. haciendo otra ve\% disertar a Sócrates: “... como decía Protágoras al declarar ser el hombre medida de todas las cosas (khrémata) de manera que tal como a mí me parecen ser las cosas (prágmata) asi son para mí. y tal como a ti así para ti". Traduzco estos pasajes según el texto en Platon. Oeurres complètes. V 2: Cratyle. ed. y trad. I.. Méridier (París, 1950: Collection des Universités de France). 53 y 62. Onta. por su parte. distancia al hombre de las cosas, pero no las desliga de él: las propone como presencias que dentro del mundo se enfrentan a la del hombre sin que éste intente, con respecto a ellas, otra operación que la de dar testimonio de su presentarse ahi. Bajo su forma épica. la palabra aparece ya al principio de la lliada $(1, \cdots .70)$ para designar el ayui y el ahora el presente de ellas, todavía en conexión con una estructura meramente lingüística de la temporalidad: “...el que conoce (Calcas) lo que está siendo ( $t$ éónta) y lo que ha sido y lo que está por ser": Homère, Iliacle. ed. y trad. P. Mazon et al. (Paris. 1949: Collection des Universités de France), I 6; e igual significado conserva todavia. bajo su forma ática, en la Helena (c. 413-412 a JC) de Eurípides. W. 14-15. “... Ilamada Theonoé porque sabie: todo acerca de los dioses, y lo que está siendo ( $t$ 'ónta) y lo porvenir": Euripide, V: Hélene, les Phéniciennes, ed. y trad. H. Cirégoire e't al. (Paris. 1950; Collection des Universités de France). 50. Pero desde el llamado fragmento de Anaximandro DK 12 B 1: “... el principio ... de las cosas ( $(\hat{o} h$ ómōn) es el ápeiron". i.e.. lo que no tiene límites ni como experimentable ni como definible .en el pensamiento de los cosmólogos presocráticos significa ya "toda existencia natural"." "hablando bajo el punto de vista platónico. lo que perciben nuestros sentidos en el mundo exterior". Así. entonces, también Heráclito: "Si todas las cosas (pámla là ónta) se convirtieran en humo. las narices discernirian" (=DK 22 B 7) e inclusive en Empédocles: "Cuando proyectaba todo el poder de su mente. observaba con facilidad cada una de las cosas ( $/$ ón ónton pánıōn) tanto en diez como en veinte vidas de hombres" (=DK 31 B 129, 4-6) -por ejemplo. "Parménides tomó evidentemente la palabra de ellos [iasimismo de Empédocles?] y a nalizó lo que implicaba lógicamente, con vistas a revolucionar el concepto ingenuo y sensible de la existencia adoptado por los milesios". Las versiones de Empédocles y' de Heráclito las extraigo de Los filósofos presocráticos. trad.C. Eggers Lan et al. (I-1II: Madrid. 1979-1980; Biblioteca Clásica Gredos, 12, 24 y 28), nos. 718 (trad. E. Juliá; I 381) y 597 (trad. F. della Croce; II 289). Y creo haber seguido muy de 
tan de aquél. Pero, ¿se trata ahora de algo que permanece situado simplemente en el orden de lo operacional ${ }^{24}$ o de algo que ha sido constituido ya en objeto relativamente a una teoría del conocimiento?25 Al mismo tiempo, ¿se trata de las cosas mismas o meramente de cosas que aparecen como modalida-

cerca en lo demás la nota 2 al segundo capítulo de W. Jaeger. La teología de los primeros filósofos griegos, trad. J. Gaos (México, 1952: uso la reimpresión de 1980: fecha del original: $1947=$ Jaeger 1947), 198. Y ver la entrada éinai (sin transliterar) en el "Wortindex" de W. Kranz (=DK III, 7-488), 144-47. En la especulación platónica, de ordinario el significado se mantiene. Al pasaje de las leles que posteriormente se aducirá (nota 26), podrian añadirse. por ejemplo. Cratilo, 385 b (habla Sócrates): "¿Y el [discurso: lógos] que dice las cosas ( $t d$ ónta) como son. es verdadero?": p. 51 de la edición mencionada más arriba: República (c. 388-c. 375? a JC) VII, 532c (habla también Sócrates. exponiendo la alegoría de la caverna): “... sombras de los seres reales (skiàs tôn óntōn)": tomo la traducción de Platón. La repúhlica. ed. y trad.J. M. Pabón y M. Fernández-Galiano, III (Madrid, 1949; Clásicos Políticos), 33; o Sofista. 263d (habla en extranjero de Elea): “... y las no cosas como cosas ( $k a \grave{~ m e ̂ े ~ o ́ m i a ~ h o s ~}$ ónta)": cf. p. 92 de la edición descrita en la nota 16. En tanto que en Jenofonte, Económico 110 (ver también más arriba), si bien ónta sigue significando 'cosas' en el sentido precedente, ocurre en un contexto que acerca tanto ese término a la noción de utilidad que casi lo hace entenderse como khrếmata. Y Jaeger 1947, loc. cit.: "En el lenguaje juridico de los oradores áticos se encuentra con frecuencia ta ónta [sin transliterar] en el sentido de lo que es propiedad de una persona". De igual manera que en 5 i la del Gorgias (c. 392-391 a JC) de Platón (habla Calicles): “... ¿o no sabes que el que imita al tirano matará. si quiere, al yule no lo imita y le despojará de sus bienes (ónta)?": Platón. Gorgias. ed. y trad. J. Calonge Ruiz (Madrid. 1951; Clásicos Políticos), 100. Por lo demás. es evidente que los referentes originales de cada uno de los tres términos hasta aqui manejados presentan una relación ineludible: los ónıa constituyen la única fuente posible tanto de los khrếmata como de los prágmata.

24 Así lo consideran, por ejemplo, Gómez. Robledo 1974, 487 o, sólo para "el campo de lo ético", también Guthrie 1969, 187. Ya antes, y más tajantemente, Marrou 1960, 84: “...ils n'ont pas été d̀ proprement parler des penseurs, des chercheurs de vérité. C’étaient des pédagogues".

25 En función de teoría del conocimiento (y del valor: o del bien, si no se admite el anacronismo) lo entienden, y lo rechazan, tanto Aristóteles como Platón. Así, en el Teetetes (369-367 a JC), Sócrates dice (166d-e). mimando a Protágoras: "Y que existan la sabiduría y el hombre sabio de ninguna manera lo niego. Antes bien, llamo precisamente sabio a aquél que, cuando ante alguno de nosotros las cosas aparecen, y son. malas, él, mediante alguna mutación. hace que aparezcan. y que sean,buenas. Sin embargo, no trates de forzar mi razonamiento de acuerdo con las palabras, sino capta más claramente lo que quiero decir. Recuerda, pues, lo que ya fue dicho, que ante el enfermo la comida aparece, y es, amarga, y ante el sano aparece, y es, lo opuesto. Ahora bien, ninguno de los dos es de considerarse más sabio que el otro: eso es imposible, ni tampoco se puede afirmar que el enfermo sea ignorante porque opina de ese modo ni que sea sabio el sano porque lo hace diferentemente. Lo que sí cabe es cambiar un punto de vista por el otro, porque el otro es mejor". $O$. endos lugares más del mismo diálogo, en ambos expresándose según su propia voz: “La sensación (áisthēsis), dijiste, es conocimiento (epistếme)? [Teetetes responde: "Sín".] Pues te has arriesgado a pronunciar una fórmula (lógos) no trivial acerca del conocimiento, sino 
des de otras cosas?26 Y, no por último, ¿a quién designa ánthrōpos? Desde el Cratilo (c. 385 a JC) de Platón, las principales lecturas antiguas postulan al hombre individual, y más explícitamente desde el Teetetes (166d): "Porque yo digo que la verdad es tal como lo he escrito: medida es cada uno de

la que asimismo enunció Protágoras. La dijo de otra manera, pero la cosa es la misma. Pues en alguna parte dice ser el hombre medida de todas las cosas, de las que son en cuanto son y de las que no son en cuanto no son" (15la-152a): y, posteriormente (16lc-d): “¿Sabes. Teodoro, lo que me asombra de tu amigo Protágoras? Teodoro responde: [“¿Qué, pues?"] Ha dicho cosas que me gustan mucho, como esa de que lo que le parece a cada uno eso además es. Sólo me pasma el principio de su razonamiento, el que al iniciar su Verdacl no haya dicho que de todas las cosas medida es el cerdo, o el cinocéfalo, o algún otro aún| más extravagante de entre quienes tienen sensación. Hubiera comenzado, así, a hablarnos magníficamente, y desdeñosamente, mostrando que mientras nosotros lo admirábamos por su sabiduria del mismo modo que a un dios, él por su parte, en cuanto a discernimiento, no era mejor que un batracio renacuajo, no digamos que cualquier otro hombre." $\mathrm{Y}$ lo mismo en diversos lugares. más o menos reiterativos. de la Metafísica aristotélica, de los cuales quizá sea oportuno recoger únicamente dos: "Además, si las contradicciones son todas simultáneamente dichas de uno mismo, es evidente que todas las cosas serán una sola. Pues será lo mismo una trirreme que un muro o un hombre. si de todo se puede afirmar o negar cualquier cosa, como necesariamente han de admitir los que hacen suyo el razonamiento de Protágoras. Pues, si alguien opina que no es trirreme el hombre, es evidente que no es trirreme; por consiguiente, también es trirreme si la contradicción es verdadera" (IV 4, 100 7b 18); y: "Semejante a lo expuesto es también lo dicho por Protágoras. Este, en efecto, afirmó que el hombre es medida de todas las cosas, que es como decir que lo que opina cada uno es la pura verdad; pues, si es así. resulta que la misma cosa es y no es, y es mala y es buena, y así lo demás que se dice en los juicios contradictorios, ya que muchas veces a unos les parece que una cosa determinada es hermosa y a otros lo contrario. y la medida es lo que le parece a cada uno" (XI 6, 1062b 12). Pero ver asimismo IV 5, 1009a 6; IX 3. 1046b 29; X 1. 1053a 31. Coherentemente. la misma perspectiva siguen las lecturas modernas que se apoyan en Aristóteles y en Platón: baste como ejemplo Guthrie 1969. 181-86. En otro orden de cosas: las traducciones de los pasajes aristotélicos proceden de Metafísica de Aristóteles, ed. trilingüe por V. García Yebra (2a. ed.: Madrid, 1982: Biblioteca Hispánica de Filosofía, 65), 180 y 554 (ver pp. 188-89, 442-45 y 488-89 para los aqui no recogidos). W. Jaeger, "La Metafísica original" y "El desarrollo de la Metafísica". en Aristóteles: bases para la historia de su desarrollo intelectual, tad. J. Gaos (México. 1946: uso la reimpresión de 1984; la edición alemana es de 1923 y de 1936.la versión inglesa, con reelaboraciones de Jaeger, de la que traduce Gaos), 194-261. sitúa las reiteraciones aristotélicas en el proceso de elaboración del tratado. al mismo tiempo que, a partir del texto actual de éste, finamente discierne las etapas de dicho proceso. Y por lo que respecta al Teetetes traduzco el texto de A. Dies en Platon. Oewres completès, VIII 2: Théétète (París, 1950; Collection des Universités de France), 170. 186 y 194.

26 De este modo W. Nestle. Historia del espiritu griego desde Homero hasta Luciano, trad. M. Sacristán (Barcelona, 1961), 118: "En todos los terrenos [üherall] ocurre pues lo mismo: las "cosas" (chrémata) de las que el hombre es medida no son cosas concretas, sino las cualidades de las cosas o las instituciones y las ordenaciones. 
nosotros (hékaston hémön) de lo que es y de lo que no".27 Pero los pasajes de Aristóteles y de Sexto que también comentan el enunciado, ${ }^{28}$ sin perjuicio de que sus autores hayan tenido acceso directo a la Verdad, ¿se hallarán exentos completamente de la influencia platónica? ${ }^{29}$ En 1895 , por otra parte, Th.

sociales [pero el texto dice: $h z w 1$. der gesellschafilichen Einrinchtungen und Ordnungen $=0$ bien de los modos de organización y de los ordenamientos sociales]. En este contexto hay que recordar que para los antiguos pensadores griegos lo caliente y lo frío. lo seco y lo húmedo eran sustancias, y que|aún en Platón (Protag. [sic] 361 B) las propiedades de la justicia. la mesura y el valor se llaman cosas (chrémata). No puede pues sorprender que también en la frase de Protágoras las cualidades se llamen "cosas". Pero la palabra "chrémata" significa al mismo tiempo lo "válido", lo que vale, como el juicio universal por una parte y hasta el mismo dinero por la otra. Para apuntar también a esta significatividad [Beziehung =referencia] y comprender correctamente el sentido de la proposición la traduciremos, pues, más adecuadamente del modo siguiente: "El hombre es la medida de toda validez (cualidad) [Geltungen (Qualitäten), las dos en plural]: de las que son en cuanto son, de las que no son en cuanto que no son". Conservo el tratamiento tipográfico de la traducción de Sacristán. Para el texto alemán ver W. Nestle, Griechische Geistesgeschichte von Homer bis Lukian in ihrer Entfaltung vom mithischen zum rationalen Denken dargestellt (2a. ed.; Stuttgart, 1944=Nestle 1944), 156-57. Y muy semejante es la posición de Guthrie 1969: "... all examples given hy Plato and Aristotle are of properties or atributes. These are all what would concern Protagoras as a teacher of politics, ethics and rethorics" (p. 19.2).

27 Habla nuevamente Sócrates-Protágoras (ver antes, nota 25). El Cratilo es más descriptivo, menos generalizador: ver, traducido al final de la misma nota 25 , el texto del pasaje.

2x De cada uno de los dos comentarios de Sexto traduzco en seguida solamente las líneas iniciales, que conceptualmente son las más próximas al texto de Protágoras y que. además. tal vez. sean las únicas necesarias para fundamentar la afirmación propuesta arriba: (a) "También Protágoras [Sexto acaba de hablar de los cirenaicos] sostiene ser el hombre medida de todas las cosas ... y mediante ello presenta únicamente lo que se manifiesta ( $(a ̀$ phaínómena) a cada uno, e introduce así la relatividad (literalmente: $t$ p̀ prós $t i=\mathrm{lo}$ con relación a alguien)": Esbozos pirronianos, 1216 (=DK 80 A 14. p. 258, 16-21): y (b) "También a Protágoras de Abdera [Sexto acaba de hablar de Anacarsis el escita] algunos lo cuentan en las filas de los filósofos que niegan el criterio (kritérion), puesto que dice que todas las representaciones (phantasias) y opiniones (dóxas) son verdaderas y que la verdad es (prós ti) relativamente a alguien, pues lo que a alguien a parece como, o lo que es opinado por alguien, inmediatamente eso es verdad para cada uno": Contra los matemáticos, VII 60 (=DK B I, p. 262. 30-273, 2). En cuanto al resto de las líneas, me parecen inobjetables dos observaciones de Guthrie 1969: "The language of Sextus is so entirely that of a later age as to cast suspicion on his substance" (p. 185) y "Sextus proves an unthrusturorthy witness of genuine Protagorean ideas when he tries to go further than the 'man-measure' statement itself and its various implications" (p. 185-86). Por lo que respecta a Aristóteles, ver la anterior nota 25 .

29 Evidentemente. Sexto no es un platónico. Pero, además del conocimiento general de la doctrina de Platón que le es necesario para acercarse u oponerse a ella desde su propia perspectiva escéptica, y más allá de su particular interés por el Timeo. 
Gomperz propuso al hombre "en sentido general (im generellen Sinn)" y, en 1940, W. Nestle al hombre "en sentido colectivo (im kollektiven Sinn)"- - esto es, "un determinado pueblo (Volk), una determinada tribu $\left(\right.$ Stamm)". ${ }^{30} \mathrm{Y}$ es posible que

en dos lugares de los Eshozos pirronianos (II 22 y 28 ) maneja pasajes del Teetetes (174b y 152a, respectivamente) y' en Contra los matemáticos, I 389-390. sigue de cerca 17la. precisamente a propósito del postulado de Protágoras. Ver Sextus Eimpiricus. ed. $y$ trad. R.(i. Bury. I-IV (Cambridge, Mass. y Londres, 1939-1959: Loeb Classical Library. 273. 291. 311 y 382). 1165 y 169 y II 207. Por otra parte. M. Untersteiner. Sofisti: testimonianze e frammenti. I: Protagora e Seniade (Florencia, 1949; Biblioteca di Studi Superiori, $4=$ Untersteiner 1949), 41, n. 14, cree encontrar conexión expresa entre la interpretación de métron como kritérion que Sexto hace en Eshoros, I 216 (ver luego, nota 36) y 160) del mismo Teete'tes: "... y según Protagoras. yo soy juer. (krités) de lo que me es en cuanto es y de lo que no me es en cuanto no es" (Sócrates habla a Teodoro).

30 Tanto esta última cita como las dos expresiones que la preceden las tomo de Nestle 1944. 158. No dispongo ahora de la obra previa de este mismo autor: Von Mythos zum Logos: ctie Sethstentfaltung der griechischen Denkens von Homer his auf die Sophistik und Sokrates. Stuttgart 1940. en donde el concepto del hombre colectivo como interpretación del anthropos de Protágoras aparece formulado por primera vez. Y de la obra de Gomper sólo conozco la traducción italiana de A. Bandini: Th. Gomperz. Pensatori greci: storia della filosofia antica. I-IV. Florencia 1933-1962. Ver ahí 11273 y $275-76$. Es de 1895 el prefacio de (iomper a la primera edición alemana de la obra: Leipzig. 1896-1897. (Guthrie 1969. 187. por otra parte. y otra ve\% para "el campo de lo ético" y nada más, parece aceptar la posibilidad de que en el enunciado de Protágoras 'hombre'signifique simultáneamente individuo y colectividad. Como se sabe, un tópico párrafo en las Historias (111 38) de Heródoto es el soporte inmediato de ta que quizá pudiera llamarse tesis colectivista: “... porque. si alguien propusiera a todos los hombres. mandando elegir de entre todas las costumbres las costumbres más hermosas. habiendo analizado, escogerian. cada uno las propias: tanto considera cada uno ser las propias costumbres mucho más hermosas. Es. pues, natural que no otro sino un hombre maniático [Cambises] ponga tales cosas como irrisión. Y yue asi han juzgado todos los hombres lo que se refiere a las costumbres. es posible calcularse por muchas otras pruebas y además también ésta: Dario en tiempo de su propio reinado. habiendo llamado a quienes de los griegos estaban junto a él, preguntaba por cuántơ dinero querian devorar a sus padres al morir: y ellos dijeron que por nada harían eso. Darío. después de eso. habiendo llamado de los indios a los llamados calatíes. los cuales se comen a sus progenitores, preguntaba, estando presentes los griegos : enterándose. mediante un intérprete, de lo que se decía. a qué precio aceptaban consumir el fuego a sus finados padres; pero ellos. exclamándo fuertemente, reclamaban que él pronunciara buenos augurios. Por tanto, así se han acostumbrado esas cosas": trad. A. Ramírez Trejo (México, 1976; Bibliotheca Scriptorum Graecorum et Romanorum Mexicana). II 24-25. Detrás de lo cual se hallan. desde luego, y sin perjuicio de la 'originalidad' de Heródoto. los llamados primeros logógrafos. Ver acerca de los más importantes de entre éstos L. Pearson. Early Ionian historians. Oxford 1939. Fragmentos en F. Jacoby. Die Fragmente der griechischen Historiker. I: Genealogie und My rhographie (Leiden. 1957), 1-156 (nós. 1-5) y 317-477 (comentario). Edición especial de Hecateo de Mileto (c. 560-c. 480 a JC: al parecer el más 
una distancia de entre tres y cinco décadas ${ }^{31}$ otorgue a una lectura mayor credibilidad que una distancia de aproximadamente veintitrés siglos y medio. Pero necesario no es.

De cualquier modo, y sin pretender disminuir la densidad de los problemas histórico-filosóficos ${ }^{32}$ implicados en ellas, tal vez sea posible intentar, más acá de las interrogantes anteriores, aunque sin ignorarlas, otra lectura de la tesis de Protágoras. Una primera proposición parece derivarse ya de los elementos hasta ahora revisados: existe ciertamente, como algo verificable en el orden de los hechos, una laxa y abierta pluralidad de cosas (ónta) con respecto a las cuales, independientemente de índoles - cuerpo, idea, propiedad, acontecimiento, etcétera - o de procedencias - de origen natural o de producción o fabricación humanas - ${ }^{33}$ la tarea intelectual inmediatamente pertinente consiste en definir el modo de la relación que a todas ellas las vincula con el hombre. Y probablemente tanto el acceso a esa definición como la serie de proposiciones que permiten completar la lectura puedan ser producidas a través de la respuesta a una nueva interrogante, que otra vez se plantea en el complejo nivel de la decodifica-

famoso de ellos en el antiguo mundo helénico): Hecataei Milesi fragmenta. ed. G. Nenci. Florencia 1954. Biblioteca di Studi Superiori 22.

31 No parece posible fechar con precisión la Verdad de Protágoras -ni siquiera los datos cronológicos más generales que acerca de la vida y obra de éste han conservado los testimonios antiguos son susceptibles de ajuste dentro de un solo esquema: ver por ejemplo K. Freeman, The pre-Socratic philosophers: a companion 10 Diels. "Fragmente der Vorsokratiker" "(3a. ed.: Oxford. 1953), 343-44. Parto aquide los siguientes supuestos: (a) Protágoras habría muerto hacia 4.14 a JC (es decir, acepto la cronología de Apolodoro en Diógenes Laercio, Vidas, IX 56=DK 80 A 1, p. 225. 8-11): (b) la conversación relatada por Sócrates en el Protágoras estaría fechada por el propio Platón en c. 432 y no en 419 a JC (es decir. considero que el anacronismo en el texto no es la presencia de los hijos de Pericles (315a) . murieron en 429 - sino la mención (327d) de la puesta en escena (420 a JC) de los Salvajes de Ferécrates); y (c) ex silentio (en ninguna parte de ninguno de los parlamentos intercambiados es mencionada o aludida la tesis del sofista), la fecha dramática del diálogo platónico proporcionaria un terminus a quo para el escrito de Protágoras. Si todo esto, por débil que sea. se admite de ese modo, la composición de la V'erdad habría ocurrido entre 45 y 25 años antes que la del Cratilo de Platón).

32 Para el tratamiento técnico de estos problemas de significado, en el orden de la técnica histórico-filosófica, ver Guthrie 1969, 181-92.

${ }_{33} \mathrm{Si}$ se toma a la letra el mito que Platón, por vo\% de Sócrates, atribuye a Protágoras en el diálogo mencionado en la nota anterior, habría que admitir también como fuente de procedencia la operación de los dioses. Pero para algunas consideraciones sobre los problemas que tal mito plantea ver después, aquí, los apartados 5 a 10. 
ción del enunciado: ¿qué es decir de alguien - no de algo - que sea métron? Técnicamente es, desde luego, una metáfora: ${ }^{34}$ una palabra ha sido desprendida de su campo habitual de significación -en sentido propio métron hace referencia o a instrumentos materiales de medición o, en cuanto han sido medidas, a las cosas también materiales a que ellos se aplican o aun sólo a ciertas porciones de tales cosas, y únicamente a eso- ${ }^{35} \mathrm{e}$ insertada en un área semántica que hasta entonces le había sido ajena. Pero esa translación no es un acto gratuito. Obedece a la necesidad de subvenir a un punto de penuria léxica en la lengua del momento - de dar primera expresión a una nota privativa del comportamiento del hombre, que anteriormente no había sido nombrada aunque asimismo es verificable en el nivel de los hechos: la de único ente en posibilidad de volver conmensurables con él los componentes de aquella imprecisa pluralidad, de tomarlos a su cargo ${ }^{36}$ y de integrarlos

34 Una catacresis. Para esta noción ver H. Lausberg. Manual de retórica literaria, trảd. J. Pérez Riesco (Madrid, 1967; Biblioteca Románica Hispánica. III 15), II 66-69 (no. 562).

35 Una vara de medir (lliada 2, v. 422), las dimensiones del mar (Hesíodo, Trabajos, v. 648), medidas de capacidad y su contenido en granos (Odisea 2, v. 355; Hesíodo, Trabajos, v. 600) o en líquidos (Iliada 23, v. 368; Odisea 9, vv 208-210: "Y cada vez que bebían de aquel vino dulce como miel, él llenaba una copa y la vertía en veinte medidas (métra) de agua"), un sistema de pesos y medidas (Heródoto, Historias, VI 127), el punto de anclaje de un navío al término de su travesía (Odisea 13, v. 11), por ejemplo. Temprano, la palabra experimentó dos extensiones semánticas - la segunda asimismo catacrética - ambas atañederas al hombre. Por una parte, hacia un aspecto de la medición de su vida: la plenitud de su edad juvenil - Hesíodo, Trahajos, v. 438 (pero tanto en Trabajos, v. 132, como en Ilíada II, v. 225, métron parece significar 'término de la adolescencia'). Por otra parte, hacia un modo de su comportamiento: la mesura (Hesíodo, Trabajos, vv. 694: "Guarda la mesura (métron): lo oportuno (kairós) es excelente entre todo" y 720 : “... el dón más pleno: la [lengua] que procede según medida (katä métron)”, por ejemplo), con la fortuna que se conoce. Es patente que el métron de Protágoras no pasa por ninguna de las dos.

36 Acaso dos pasajes en el libro IV de las Leyes del Platón anciano justifiquen esta proposición. En $716 c$, el Ateniense dice: "El dios ciertamente ha de ser nuestra medida de todas las cosas (pänton khrẻmátön métron), mucho mejor que el hombre, como por ahí suelen decir". Y antes, en $715 \mathrm{e}-716 \mathrm{a}$, solemnemente habia proclamado: “... el dios, que según el antiguo dicho, tiene en sus manos el principio, el fin y el medio de todas las cosas (ho mèn dè theós, hớsper kaì ho palaiớs lógos, arkhến te kai teleutè̀n kai mẹésa tôn óntōn hapántōn ékhön) ..." Ya Jaeger 1936, I 317, cita la primera expresión, para diverso propósito. Translado ambos párrafos, la traducción del segundo con ligeras modificaciones en la colocación de las palabras, de Platón, Las leyes, ed. y trad. J. M. Pabón y M. Férnández-Galiano (Madrid, 1960; Clásicos Políticos). I 146-47. También E. des Places en Platon, Oeuvres complètes, XI 2: Les 
en un orden cognoscitivo y axiológico ${ }^{37}$, obra exclusiva suya, que les confiere ser y valer en cuanto khrếmata (o en cuanto prágmata). Nunca en cuanto cosas con respecto a las cuales se entiende que el hombre no ha sido enfrentado a ellas. ${ }^{38}$ Puesto de otra manera: en la tesis de Protágoras el hombre es definido en función de su unicidad como creador de cultura - concebida ésta no como una más o menos inconexa colección de habilidades sino como la organización y operación de un mundo. Y si todo esto es así — valga la insistencia: no en la

lois, livres III-VI (París, 1951; Collection des Universités de France), 65, traduce ékhön como "qui a dans ses mains", y, antes, B. Jowett. The dialogues of Plato translated into English with analyses and introductions (3a. ed.; Oxford, 1892=Jowett 1892; uso la reimpresión de 1931), v 99: "holding in His hands"-- lo que respeta más el aspecto durativo de la acción implicado en ékhön. "Holds in his hands" dice en su versión al inglés (desconozco el original), certificada por el autor, la paráfrasis hecha por P. Friedländer, Plato (Princeton, 1958-1969; Bollingen Series, LIX; fechas de la segunda edición alemana: 1954-1969) =Friedländer 1954-1969), III 432. Creo entender, por otra parte, que tanto el propio Platón en el Cratilo y en el Teeietes (ver los pasajes aducidos en las anteriores notas 25 y 29) como Aristóteles (Metafísica $X 1,1053 a$ 32: "Y Protágoras afirma que el hombre es medida de todas las cosas como si dijera que $\overline{l o}$ es el que sabe y el que siente, y esto porque tienen el uno sensación y el otro ciencia. que decimos que son medida de sus objetos"; trad. García Yebra, p. 489), Sexto Empírico (Eshozos pirronianos, I 216: "Llama [Protágoras] métron al criterio": texto en DK 80 A 14) y aun, sea quien haya sido, Hermias 'el filósofo'(s. V.VId JC) en su Escarnio de los filósofos paganos, 9: "Límite y criterio (hóros kaĭ krísis) de las cosas es el hombre" (texto en DK 80 A 16) otorgan a la palabra métron una dimensión estrictamente cognoscitiva. Me queda la impresión de que esta segunda postura no necesariamente invalida la aquí adoptada. Otra cosa: del Escarnio de Hermias hay traducción al español en Padres apologistas griegos: s. II, ed. y trad. D. Ruiz Bueno (Madrid, 1954; Biblioteca de Autores Cristianos, IIl 116), 879-88.

${ }_{37}$ No de cosa diferente parecen haber estado ocupándose, a partir de sus propias concepciones del ser, Aristóteles y Platón con respecto a la tesis de Protágoras.

38 Para los dos modos de esta situación, las palabras griegas son otras. En el Timeo (c. 361 a JC) de Platón. a las cosas que el demiurgo produce antes del advenimiento del hombre - esto es, a las cosas pensadas como sin el hombrecuando se quiere no especificarlas se las denomina, no siempre con matices claramente distinguibles, ho kósmos (29a), tò pân (29d), pánıa (69b), hólos (30b) - y el cuerpo del mundo, por ejemplo, es designado lo mismo como toû pantôs sôma (3lb) que como toû kósmou sôma (32c). Ver Platon, Oeưres complètes, X: Timée. Critias, ed. y trad. A. Rivaud (París, 1956; Collection des Universités de France), $141-45$ y 195 . Y esos mismos términos, aunque desde puntos de vista bastante diferentes, son empleados por los cosmólogos presocráticos cuando éstos toman como referente al conjunto de las cosas del que el hombre todavía no se ha visto diferenciado - es decir, a las cosas pensadas con el hombre existente ya pero aún no especificamente propuesto en la relación de sujeto a objeto con respecto a ellas. Ver las entradas kósmos (especialmente bajo el sub-encabezado Weltall), hólos, pâs y pánta (sin transliterar) en DK III $240-43,307$ y $337-4 i$. 
perspectiva estrictamente histórico-filosófica- no parece darse incompatibilidad en que sean el hombre genérico o el hombre colectivo o el hombre individual los señalados como responsables de esa operación. $\mathrm{O}$, fuera ya del texto, la interacción de todos ellos.

Continuará

N. del E.: por uv: lamentable error de nuestra parte, en el ensayo "Sofistas, dioses y literatura", que aparece en el numero anterior de Estudios, hay una errata imperdonable: dice Sócrates y debe decir Sofocles. (Cfr. p. 79, cuarta línea). 